\title{
Electronic Payment Systems (E-payments) and Nigeria Economic Growth
}

\author{
John Sylvester Afaha ${ }^{1,2}$ \\ ${ }^{1}$ Department of Economics, Caleb University, Imota Lagos State, Nigeria \\ ${ }^{2}$ Center for Petroleum Economics, Energy and Law (CPEEL) University of Ibadan, Oyo State, Nigeria
}

Email address:

johnafaha@yahoo.com

To cite this article:

John Sylvester Afaha. Electronic Payment Systems (E-payments) and Nigeria Economic Growth. European Business \& Management. Vol. 5, No. 6, 2019, pp. 68-78. doi: 10.11648/j.ebm.20190506.11

Received: October 14, 2019; Accepted: November 8, 2019; Published: November 19, 2019

\begin{abstract}
The electronic payment system is a platform that settles financial transactions between the buyer and seller. Payment systems are meant to ease the stress of both parties making an easy exchange or flow of money in a safe and secure environment. This study statistically estimated the relationship between electronic (e-payment) systems and economic growth in Nigeria. Monthly available Data for Nigeria on values of various payments systems were analyzed using Autoregressive Distributed Lagged regression (ARDL) method covering the period of (2012-2017). The result indicates a significant positive relationship between the electronic payment system and economic growth in terms of real gross domestic product (GDP) growth. Automated teller machines have a positive significant impact on economic growth, based on a probability of $(0.06)$, but its contribution to the real GDP growth is negative ( -5.0 percent). This means the ATM based transaction encourages more cash, possessions and may not yield the required goal of low cash based transactions within Nigeria's banking populace. POS contributes 17 percent growth to the real GDP growth in Nigeria, web based transactions (WBT), contributes 2.3 percent to the real GDP growth, but INTERBANK transactions, has an insignificant impact on GDP growth while MOP has a negative contribution to the impact on real GDP growth. Point of Sales (POS) transactions is also the most patronized electronic banking tool and this is seen from the descriptive analysis, followed by web base transactions (WBT). POS and WBT have the highest average amongst all other variables. This implies that POS and WBT are significantly part of the major determining factors influencing and contributing to the real GDP growth output in Nigeria, while other variables such as INTERBANK transactions are although relevant but contributes minimally and drive real GDP output negatively down, as reflected in the results. Since the successful implementation of the e-payment systems which has much to do with internet connectivity and mobile banking, efforts should be made to design or improve on the internet security framework to check online fraud. There should be adequate legislation on all aspects of the operations of the e-banking and cashless system so that both the operators of the system and the public can be adequately protected.
\end{abstract}

Keywords: Electronic Payment System, Interbank, Economic Growth, Point of Sales

\section{Introduction}

The evolution of technology with the rapid growth in Information and Communication Technology (ICT) across the globe, techniques for completing business transactions are quickly moving from a conventional system to an electronic payment system. The payment system is an operational network governed by laws, rules and standards that links bank accounts and provides the functionality of monetary exchange using bank deposits [21]. The payment system is the infrastructure consisting of institutions, instruments, rules, procedures, standards and technical means established to affect the transfer of monetary value between parties discharging mutual obligations. Its technical efficiency determines the efficiency with which transaction money is used in the economy and risk associated with its use [6].

What makes it a "system" is that it employs cash substitutes with the use of electronic money and other ICT related equipment in its operations. Traditional payment systems are negotiable instruments such as draft cheques and 
documentary credits such as letter of credits. With the advent of computers and electronic communications a large number of alternative electronic payment systems have emerged. These include debit cards, credit cards, electronic funds transfers, direct credits, direct debits, internet banking and ecommerce payment systems. Some payments include credit mechanisms, but that is essentially a different aspect of payment. Payment systems are used in lieu of tendering cash in domestic and international transactions and consist of a major service provided by banks and other financial institutions. Payment systems may be physical or electronic and each has its own procedures and protocols. Standardization has allowed some of these systems and networks to grow at global scale, but there are still many countries and product- specific systems. Examples of payment systems that have become globally available are credit card and automated teller machine networks. Specific forms of payment systems are also used to settle financial transactions for products in the equity markets, bond markets, currency markets, futures markets, derivatives, option markets and to transfer fund between financial institutions both domestically using clearing and Real Time Gross Settlement (RTGS) Systems and internationally using the SWIFT network [19].

Electronic Payment Systems (EPS) apart from their convenience and safety also have a significant number of economic benefits which include mobilising savings and ensuring most of the cash available in the country are with banks. This will make funds available to borrowers both businesses and individuals. Furthermore, an electronic payment system has the ability to track individual spending; to facilitate the design of products by the banks. This information is also useful to the government when making decisions. EPS also have the ability to reduce cash handling and printing costs.

Notwithstanding, it has been observed that despite the recent developments and initiatives by the central bank of Nigeria (CBN) to automate the Nigerian payment system, the use of cash is still dominant among financial transactions in Nigerian Banking sector. The Advance Fee Fraud codenamed 419 or scam, is one of the most popular Internet frauds and it probably had its origin from Nigeria. The government had instituted a number of regulatory measures to curb the tide of frauds. These include: the Bank Verification Number (BVN), which is a centralized biometric identification system for the banking industry launched on February 14th, 2014 through the Central Bank of Nigeria through the Banker' Committee and in collaboration with all banks in Nigeria. The Treasury Single Account (TSA) which is a financial policy in use in several countries all over the world. It was proposed by the federal government of Nigeria in 2012 under the Jonathan Administration and was fully implemented by the Buhari Administration. The National Drug Law Enforcement Agency (NDLEA) Act of 1989; the Failed Bank (recovery of debt and financial malpractice of banks) Act of 1994: the Money Laundering Act of 1995; and the Anti-corruption Act of 1999 [12].
Similarly, the other bodies constituted to check the menace of fraud are: the National Cybercrime Working Group (NCWG); the Economic and Financial Crimes Commission (EFCC), Independent corrupt practices commission (ICPC), among others. All these have not yielded much fruits because it takes more than legislation and enforcement to effect a change, but it also demands general attitudinal, cultural and social change on the part of all and sundry. Government had equally instituted a number of systems to facilitate interbank settlement and funds dispensation to individuals. The systems include: Nigerian Center Switch (NCS), which have subservices as follows: the Nigerian Interbank Settlements System (NIBSS); the Nigerian Electronic Funds Transfer (NEFT); the Nigerian Automated Clearing System (NACS); and the Society of Worldwide Interbank Financial Telecommunication (SWIFT), of which Nigeria is a member, Others are; Nigeria Interbank Settlement System Instant Payment (NIP), Point of Sale terminals (PoS), Automated Teller Machine (ATM) and Unstructured Supplementary Service Data (USSD), amongst others. Quick teller and fintech companies (such as Paylater, Aella credit, Branch co., Palm Credit, amongst others), have also been introduced and have commenced operations in other to ease Banking, loans and Bills payment transactions $24 \mathrm{hrs}$ a day.

Currently, InterSwitch is at the forefront of providing facilities for e-payment implementation in Nigeria. It operates an integrated, secure, auditable and open platform for financial transactions, e-commerce, telecommunications, value-added services, e-billing and payment collection and monitoring (InterSwtch). The other parties involved in the epayment revolution include some banks, switching companies, cards companies and the telecoms operators in Nigeria [1]. What has given the country a respite is the fact that InterSwitch has currently been appointed Gold Partner by Thales e-security: a global industry leader in WAN data encryption [15]. By this feat, InterSwitch will be handling the security infrastructure of West and Central African region. Therefore, the problem of the country is not the technical know-how to safeguard a secure e-payment transaction but attitudinal.

Similarly, due to the political, social and economic conditions of the country, this policy is not without its constraints. The change from cash based economy to cashless economy moved people away from their comfort zone. This discomfort and the lack of clarity and understanding, had hampered the adoption and fuelled conspiracy theories amongst stakeholders, [7]. Hence CBN maintains that lack of understanding of cash policy amongst the banked and unbanked, resistance due to prevailing cash culture, "Techno -phobia, illiteracy, entrenched poverty (can't spend what you don't have), infrastructure lag, distrust in banking system, lack of clarity in communicating content of policy and inadequate payment terminal service providers (PTSPs) capacity among others are challenges that hinder the effectiveness of cashless policy in the country. Akhalumeh \& Ohiokha observed some challenges with the introduction of cashless policy and their findings show that $34.0 \%$ of the 
respondents cited problem of internet fraud, $15.5 \%$ cited problem of limited POS/ATM, 19.6\% cited problem of illiteracy and $30.9 \%$ stayed neutral [4]. While in some quarters there was fear of unemployment, some believe it will create more jobs especially when companies manufacturing POS machine are sited in Nigeria. Based on this validation, the article intends to answer the following research questions; (i) what impact do point of sale, web based transaction and other forms of e-payments have on Nigeria's economic growth? (ii) What is the impact of automated teller machine and mobile payments on Nigeria's economic growth? The underlisted objectives of the study which were later estimated are specified; (i) to estimate the impact of point of sale and web based transaction on economic growth. (ii) to investigate the significant impact of automated teller machines and mobile payments on economic growth.

\section{Literature Review}

\subsection{Evolution of Electronic Payment System in Nigeria}

The E-payment system is a platform that settles financial transactions between the buyer and seller. Payment systems are meant to ease the stress of both parties making an easy exchange or flow of money in a safe and secure environment. Electronic payment is a relatively new phenomenon in Nigeria. Most transactions in the country are done with cash. This is because cash remains the preferred medium for payment in the country. Poor awareness of e-payment solutions, ignorance, poor banking culture, lack of trust, illiteracy and the love for the status quo have been fingered as responsible for the high volume of cash transactions in Nigeria [20]. Payments across Nigeria has changed, they are now digitalized giving rise to online payments in Nigeria which have helped a lot of people grow their business online because it breaks the physical barrier of processing cash transactions manually. Payments are still done physically with cash exchange in Nigeria but we can't ignore online payments we live in a digital era where the Internet has brought about transformational change to our lives. The Nigerian Communications Commission (NCC) in 2017 stated that the number of internet users in Nigeria increased to 91.6 million that's 91,598,757 active internet users in Nigeria. In Nigeria, we started with cash payments which included cheque payments then we moved to electronic payments in 2012. Electronic payment systems opened the doors other forms of payment systems in Nigeria. Electronic payment system moved to online payments, card payments, mobile payments, online banking and others. In 2018, online payments system has grown tremendously with the help of the internet [10].

Cheques for many years have been the only option to cash in the economy. However cheques have not been acceptable to merchants because of corruption and the resultant mistrust that it creates. For any payment system to be able to replace cash (or at least compete with it) it must win the trust of merchants in the economy. For this to happen there must be a way for merchants to verify the validity of the purchase. This is where e-payment or e-transactions solutions come in. These payment solutions target most of the concerns of merchants and more. However, despite its advantages epayment solutions have not gained much ground. The Automated Teller Machine (ATM) is the most popular etransaction solution in Nigeria. ATM is popular because of its convenience. With ATM, it is a lot easier to withdraw money or to check account balance. However, despite its popularity the ATM has done very little in reducing the amount of cash in the economy. This is because most Nigerians use ATM only for cash withdrawal. Although ATM machines can perform other functions like fund/cash transfer, mobile phone credit recharge and bills payment, cash withdrawals and balance inquiry remain the most popular applications sort after by users in Nigeria.

InterSwitch, VPay, ETranzact, and QuickCash are some of the leaders in ATM deployment in Nigeria. InterSwitch today has all banks in the country connected to her network. This actually makes it possible to use their cards in all bank branches nationwide and in almost all machines. Different ATM service providers are also interconnected so you do not need to worry which company services a particular ATM machine. InterSwitch for example supports Visa and MasterCard on her ATM machines and vice versa. Because ATM machines are mainly used for cash withdrawals, they do not go far enough in turning Nigeria into a cashless economy. ATM only makes more cash available in the economy because of the ease at which depositors can withdraw cash. To turn Nigeria into a cashless economy we need more than just ATM cards, we need credit/debit cards [20].

While ATM cards make cash withdrawal convenient (thereby contributing to the problem), Credit cards, Debit cards, and e-wallets (like mobile money) makes cashless shopping a lot more convenient. Hence to turn the country to a cashless economy the drive should be towards credit cards, e-wallets and debit cards. While ATM cards require ATM machines to operate, Credit and debit cards require a Point of Sale (POS) terminal. POS terminals are located at accredited retail shops (merchant). These merchants accept credit and debit cards as means of payment by customers. Credit and Debit cards like Visa, InterSwitch, and MasterCard can also be used to purchase from merchants on the internet. It is important to note that most ATM cards in Nigeria like InterSwitch can also be used as Debit cards and vice versa. InterSwitch and Unified Payments are leaders when it comes to e-payment solutions in the country. InterSwitch ATM card is supported by all banks in Nigeria. InterSwitch ATM/Debit cards also allow cardholders to shop on the internet from merchants in the country. Valucard has the VPay, which is an online chip, and PIN card that in addition to being used at POS terminals for electronic payment can also be used to buy from local merchants on the internet. VPay can serve as either credit or debit card. VPay can also be used for cash withdrawal at ATM machines.

Valucard is the joint acquirer of Visa international in Nigeria. They provide Visa payment solutions to their customers. With Visa, card holders can purchase from any 
merchant anywhere in the world were Visa is accepted. And that means anywhere in the world. Valucard also promotes the Verified by Visa service $(\mathrm{VbV})$, which is a simple password protected identity-checking service that makes purchasing online more secured. VbV allows Visa and VPay cards to be used for secured internet payments from all visa merchants worldwide. $\mathrm{VbV}$ also allows merchants based in Nigeria to sell to card holders worldwide. Moving forward it is obvious that e-payments has a lot of contribution to the economy; this maybe evidently confirm looking at the table below a trend analysis of the contributions can be observed.
See table one (1) below: thereforeIt is imperative to briefly explore e-Payments, money transfer, cash transactions and cash outside the banking system in Nigeria since the introduction of cashless policy in 2011 as follows: The Electronics Transactions include: Cheques, NIBSS Instant Payment (NIP) and (NEFT), Automated Teller Machines (ATM), Point of Sales (POS), Web (Internet), Mobile payment (MMO), REMITA, NAPS, M-Cash and Central Pay. According to $\mathrm{CBN}$ annual statistical bulletin, the analysis of trends of both volume (Absolute No) and the Naira value of the electronic transactions are:

Table 1. Contributions and trend analysis of E-payments Transactions in Nigeria.

\begin{tabular}{|c|c|c|c|c|c|c|}
\hline & 2017 & 2016 & 2015 & 2014 & 2013 & 2012 \\
\hline Cheques & $10,808,983$ & $11,719,847$ & $13,466,461$ & $15,283,933$ & $14,211,078$ & $12,161,694$ \\
\hline NEFT & $31,034,624$ & $29,754,182$ & $28,935,605$ & $29,690,765$ & $29,834,317$ & $28,941,559$ \\
\hline ATM & $800,549,099$ & $590,238,934$ & $433,695,748$ & $400,269,140$ & $295,416,724$ & $375,513,154$ \\
\hline POS & $146,267,156$ & $63,715,203$ & $33,720,933$ & $20,817,423$ & $9,418,427$ & $2,587,595$ \\
\hline WEB & $28,991,097$ & $14,088,247$ & $7,981,361$ & $5,567,436$ & $2,900,473$ & $2,276,464$ \\
\hline MMO & $47,804,561$ & $47,053,252$ & $43,933,362$ & $27,744,797$ & $15,930,181$ & $2,297,688$ \\
\hline EBILLSPAY & 905,941 & $1,026,886$ & $1,208,556$ & 593,579 & 557 & \\
\hline REMITA & $39,706,264$ & $38,249,886$ & $19,417,371$ & $15,029,627$ & & \\
\hline NAPS & $11,900,008$ & $3,965,212$ & 936,667 & & & \\
\hline M-CASH & 77,832 & & & & & \\
\hline CENTRALPAY & 375,356 & 70,239 & 66,031 & & & \\
\hline Total & $1,489,291,593$ & $953,498,338$ & $654,585,640$ & $555,826,554$ & $384,823,915$ & $428,227,808$ \\
\hline$\%$ change $2012-2017$ & $36 \%$ & $31 \%$ & $15 \%$ & $31 \%$ & $-11 \%$ & $10 \%$ \\
\hline
\end{tabular}

Source: Central Bank Statistical bulletin (online), 2018.

From table 1 above it is obvious that the volume of epayments have increased over the period from 2012 (a $10 \%$ decrease) to 2017 (36\% increase). It is clear that the Nigerian banking population are gradually embracing the e-payment transactions channels for everyday business.

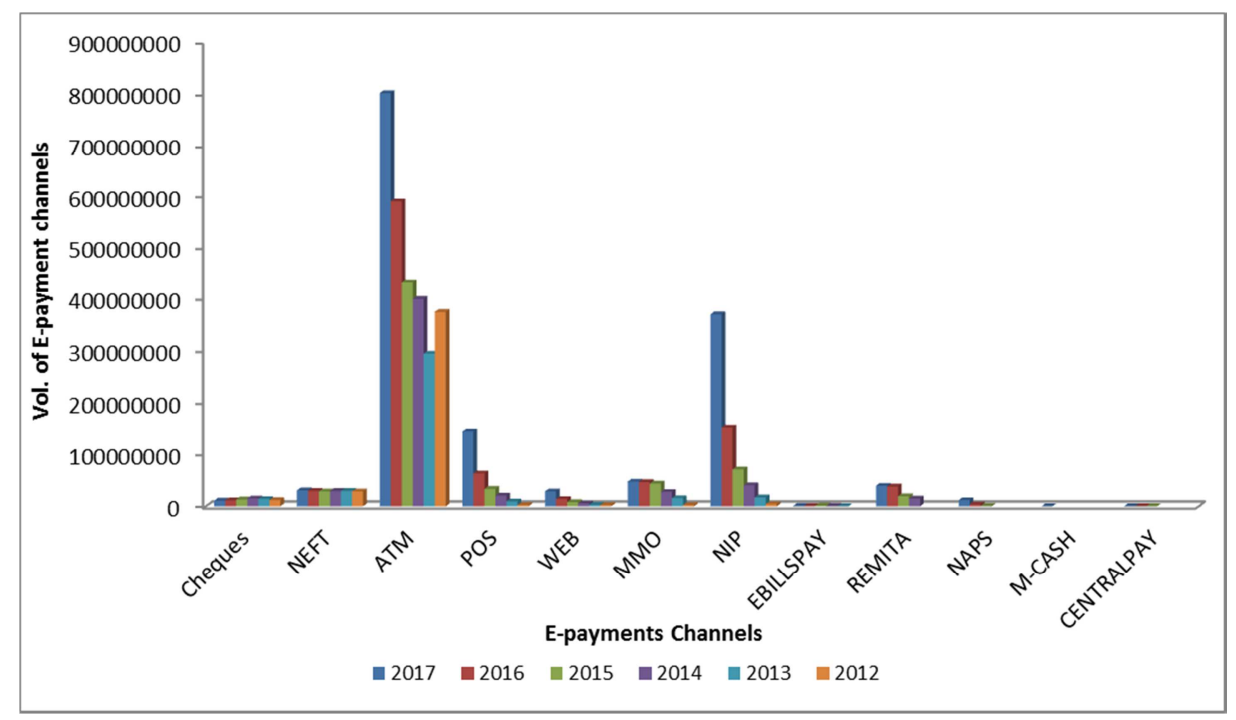

Source: Central Bank Statistical bulletin (online), 2018.

Figure 1. Volume of E-payment Channels from 2012-2017.

Figure 1 above shows that the $\mathrm{CBN}$ figures indicate a general increase in the absolute volume of electronic transactions. The smallest increase was recorded in M-cash transactions and the highest was in ATM use, though NIP also experienced general increasing tendency. Interestingly, POS volume experienced decreased within this period, reason may be because of Internet Network services that affects POS transactions. 


\subsection{Concept of Electronic Payment (E-payment) Economy}

E-payment system is a way of making transactions or paying for goods and services through an electronic medium without the use of check or cash. It's also called an electronic payment system or online payment system. Read on to learn more. The electronic payment system has grown increasingly over the last decades due to the widely spread of internetbased banking and shopping. As the world advance more on technology development, a lot of electronic payment systems and payment processing devices have been developed to increase, improve and provide secure e-payment transactions while decreasing the percentage of check and cash transaction. The electronic payment system has grown increasingly over the last decades due to the widely spread of internet-based banking and shopping. As the world advance more on technology development, a lot of electronic payment systems and payment processing devices have been developed to increase, improve and provide secure epayment transactions while decreasing the percentage of check and cash transaction. E-payment economy does not mean an outright elimination of cash transactions in the economic setting but one in which the amount of cash-based transactions are kept to the barest minimum. According to [26], cashless economy is defined as one in which there are assumed to be no transactions frictions that can be reduced through the use of money balances, and that accordingly provide a reason for holding such balances even when they earn rate of return. The following among others enhance the functioning of cashless economy; e-finance, e-banking, emoney, e-brokering, e-exchanges etc. In a modern economy, the use of noncash payment methods such as cards (credit and debit) dominates the use of cash in payments [3].

The E-payment policy initiative of the Central Bank of Nigeria is a move to improve the financial terrain of the economy. The policy aims at reducing (not eliminating) the amount of physical cash (coins and notes) circulating in the economy, and to encourage more electronic-based transactions (payments for goods, services, transfers). A cashless society is a culture where no one uses cash, all purchases being made are by credit cards, charge cards, cheques, or direct transfers from one account to another through mobile banking or other electronic money transfer modes. The cashless society refers to the widespread application of computer technology in the financial system [17]. Considering the success potential of this policy [13] opined that "in the long run sustainability of the policy will be a function of the endorsement of, and compliance by endusers". According to Central Bank of Nigeria [9] the policy is expected to reduce cost incurred in maintaining cash-based economy by $90 \%$ upon its full implementation.

\subsection{Theoretical Underpinnings of Electronic Payment System}

In theory, the relevance of the electronic payment systems in economic growth of Nigeria can be found within the context of the theory of payment system efficiency and central bank monopoly, the proponents of this theory [8] argued that, the central banks gradually lose their monopoly position in the provision of liquidity combined with its subsequent small size which makes it hard to control the term interest rates. They further argue that increased usage of cashless banking instruments strengthens the monetary policy effectiveness and that the current level of e-money usage does not pose a threat to the stability of the financial system, roger's diffusion of innovation (DOI) theory; the diffusion theory of innovation is a model developed to predict factors influencing adoption of information system [21]. Literature on Information Technology (IT) diffusion emphases the importance of perceived relative advantage and improved organizational performance as enablers of adoption of new innovation. [22], stated that the greater the perceived relative advantage, the faster the adoption. The diffusion of innovation theory posits that potential adopters evaluate an innovation based on innovation attributes such as relative advantage, compatibility, complexity (ease of use), trial ability, and observability, theory of reasoned action (TRA); [14] demonstrated TRA as a model in social psychology that can explain virtually any human behavior. It assumes that individuals are usually quite rational and make a systematic evaluation of information made available to them. Theory of planned behaviour (TPB); the TPB was introduced by [5] TPB encompasses the TRA and extends it. Both theories establish that behavior is a direct function of behavioural intention [24]. However, the TPB differs from the TRA, since it includes a new construct, the Perceived Behavioral Control (PBC). Technology acceptance model (TAM); TAM is an information system theory that models the acceptance and use of technology. TAM as proposed by Davis [11] is an extension of the Theory of Reasoned Action (TRA) and the Theory of Planned Behavior (TPB). TAM puts forward, two theoretical constructs; perceived usefulness (PU) and perceived ease of use (PEOU) as fundamental determinants of users' acceptance of an information system.

The core theory which was adopted and aliened with the research is the Diffusion of Innovation theory (DOI) developed by [21], which is pertinent to the explanation of the causality between the pertinent variables. It is germane to this study because economics operates within fairly well established and generally accepted overarching frameworks that can guide investigations $[18,21]$ sighted that innovation is diffused to members of a social system over time. However, in the context of the present study, diffusion is spread where diffusion is the spread of cashless payment where consumers seek improved and convenient transaction, while businesses seek new profit opportunities. Consequently, [25] were of the opinion the diffusion of cashless payment will result in the adoption of cashless transactions within the society or community, subject to the types of innovation adopters and innovation-decision process, therefore, since the consequences of diffusion in cashless payment depend on how quickly the society is willing to adopt cashless payment through different stages of innovation processes, the consequences of the adoption of cashless payment differs in different society. 


\section{Methodology}

In order to measure the relationship between the adoption of e-payment systems and economic Growth, the following mathematical ARDL construct where developed:

$$
\mathrm{RGDP}=\mathrm{f}(\text { E-Payment })
$$

RGDP $=$ F (WBT, POS, ATM, MOP, INTERBANK) $(2)$

Using equation (2) the general ARDL representation is specified as:

$$
\begin{aligned}
& \Delta \mathrm{RGDP}_{\mathrm{t}}=\alpha_{0}+\sum_{\mathrm{i}=1}^{\mathrm{n}} \phi_{\mathrm{i}} \Delta \mathrm{RGDP}_{\mathrm{t}-\mathrm{i}}+\sum_{\mathrm{i}=0}^{\mathrm{p}} \vartheta_{\mathrm{i}} \Delta \mathrm{WBT}_{\mathrm{t}-\mathrm{i}}+\sum_{\mathrm{i}=0}^{\mathrm{q}} \Omega_{\mathrm{i}} \Delta \mathrm{POS}_{\mathrm{t}-\mathrm{i}} \\
& +\sum_{\mathrm{i}=0}^{\mathrm{k}} \gamma_{\mathrm{i}} \Delta \mathrm{ATM}_{\mathrm{t}-\mathrm{i}}+\sum_{\mathrm{i}=0}^{\mathrm{s}} \Psi_{\mathrm{i}} \mathrm{MOP}_{\mathrm{t}-\mathrm{i}}+\sum_{\mathrm{i}=0}^{\mathrm{v}} \tau_{\mathrm{i}} \Delta \mathrm{INTERBANK}_{\mathrm{t}-\mathrm{i}}+\lambda_{1} R G D P_{t-1}+\lambda_{2} \mathrm{WBT}_{\mathrm{t}-1} \\
& +\lambda_{3} \operatorname{POS}_{t-1}+\lambda_{4} \operatorname{ATM}_{t-1}+\lambda_{5} \text { MOP }_{t-1}+\lambda_{6} \operatorname{INTERBANK}_{t-1}+\varepsilon_{t}
\end{aligned}
$$

Where all variables are as previously defined, $\Delta$ is the difference operator and $e_{t}$ is the error term. To trace the existence of cointegration, F-statistic is computed from OLS regression of equation (3). The null hypothesis of no cointegration is tested by restricting the lagged level variables equal to zero (i.e. $\lambda_{1}=\lambda_{2}=\lambda_{3}=\lambda_{4}=0$ ) against the alternative hypothesis that $\lambda_{1}=\lambda_{2}=\lambda_{3}=\lambda_{4}=0$. The bounds tests provide two asymptotic critical value bounds. The lower bound assumes variables are $I(0)$ whilst the upper bound assumes $I(1)$ variables. The null hypothesis of no cointegration is rejected if the computed F-statistic is greater than the upper critical value bound; otherwise the null hypothesis is not rejected.

Based on equation (3) the following ARDL based error correction model required for the short run result is specified as follows:

$$
\begin{aligned}
& \Delta \operatorname{RGDP}_{\mathrm{t}}=\alpha_{0}+\sum_{\mathrm{i}=1}^{\mathrm{n}} \phi_{\mathrm{i}} \Delta \mathrm{RGDP}_{\mathrm{t}-\mathrm{i}}+\sum_{\mathrm{i}=0}^{\mathrm{p}} \vartheta_{\mathrm{i}} \Delta \mathrm{WBT}_{\mathrm{t}-\mathrm{i}}+\sum_{\mathrm{i}=0}^{\mathrm{q}} \Omega_{\mathrm{i}} \Delta \mathrm{POS}_{\mathrm{t}-\mathrm{i}} \\
& +\sum_{\mathrm{i}=0}^{\mathrm{k}} \gamma_{\mathrm{i}} \Delta \mathrm{ATM}_{\mathrm{t}-\mathrm{i}}+\sum_{\mathrm{i}=0}^{\mathrm{s}} \Psi_{\mathrm{i}} \mathrm{MOP}_{\mathrm{t}-\mathrm{i}}+\sum_{\mathrm{i}=0}^{\mathrm{v}} \tau_{\mathrm{i}} \Delta \mathrm{INTERBANK}_{\mathrm{t}-\mathrm{i}}
\end{aligned}
$$

Variable definitions: RGDP = Real Gross Domestic Product; WBT $=$ Web Based Transaction; POS = Point of Sales; ATM = Automated Teller Machine; MOP = Mobile Payment; INTERBANK = Interbank money transfer transactions.

\subsection{Empirical Results}

The results of the ARDL regression show that at all levels of significance, the coefficients of the last two years real GDP (lagged), POS (lagged two years), WBT and INTERBANK lagged for the current year showing they are statistically significant. This implies that last year POS, WBT, and INTERBANK and other years lag identified above are part of the major determinant factor influencing real GDP growth of output in Nigeria, while other years not cited above are less important in driving real GDP output, as reflected in our results. The result revealed a negative elasticity coefficient of 0.075 for INTERBANK on real GDP output growth in Nigeria, though significant. This means that a $1.0 \%$ rise in INTERBANK would dampen growth in GDP per capita by $7.5 \%$, while the similar rise in WBT would raise it by 0.23 percent with a significant value of 0.05 . Other variables as mentioned earlier shows the expected aprori signs and a statistically significant based on the respective probabilities except for ATM and MOP where none of the Lagged where significant. In general, the fit of the regression equations in Table 5 is very good $\left(R^{2}=0.99\right.$ and adjusted $\left.R^{2}=0.99\right)$ as can be seen from the Table 5 above. The R-squared shows that all the independent variables in our model explain approximately $99 \%$ of the variations in output growth per capita (dependent variable) in the period under consideration. Also, the joint Ftest statistic value of 1315.455 was found significant (0.0000) at all levels, showing the test for testing jointly the inclusion of all the variables in the model. Pertinent to the above, the Durbin-Watson (DW) statistic (measure for the presence of autocorrelation in the model) is 2.07 , it is noticed therefore, that our model is free from autocorrelation as the value is 2 . This means that the model is reliable in explaining the relationship between cashless policy and economic growth in Nigeria.

In conclusion the e-payment tools/mechanisms (i.e. Point of Sale, Automated Teller Machine, Web-based Transfers, Mobile Payments, and Inter-Bank Transfers) has been neglected in prior studies in Nigeria. Arguably, the recent trend in the development of cashless policy can be traced to the evolution in the information technology and innovation in mobile devices; one may therefore say that continuous innovation in technologically aided payment system as supported by Rogers (1969) in his Diffusion of Innovation (DOI) theory will surely expand the society's accessibility to cashless payment. As presented in the result, cashless policy adoption can only influence economic growth in the long run. Hence, the policy set to promote cashless policy will not affect the economy immediately.

Since the successful implementation of the e-payment policy which has much to do with internet, efforts should be made to design or improve on the internet security framework to check online fraud. There should be adequate legislation on all aspects of the operations of the e-banking 
and cashless system so that both the operators of the system and the public can be adequately protected. Hence, this will avert undue advantages and discourage impunity, hidden, and sub-charge. Government should increase public awareness campaigns on cashless policy and its benefit so as to ensure that the consumers get the right information as pertains to cashless payment methods on transactions. The Nigerian apex bank should anticipate changes to expect in the progress of the cashless payment method and channel it in such a way to ensure the safety, efficiency and effectiveness of domestic and international banking system.

RGDP (N'Billions)

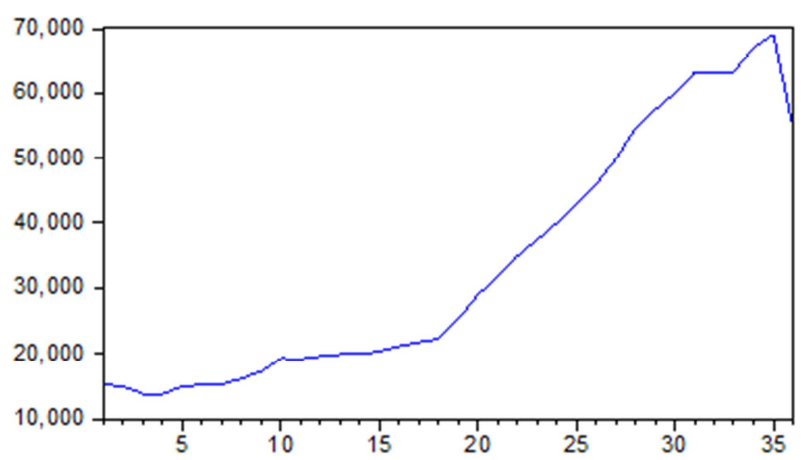

Point Of Sale (POS) transactions: value

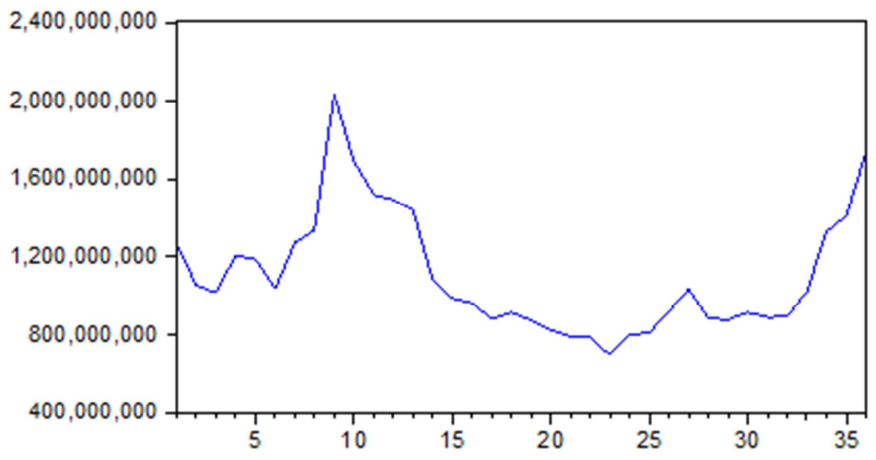

Interbank Funds Transfers: value (N' Million)

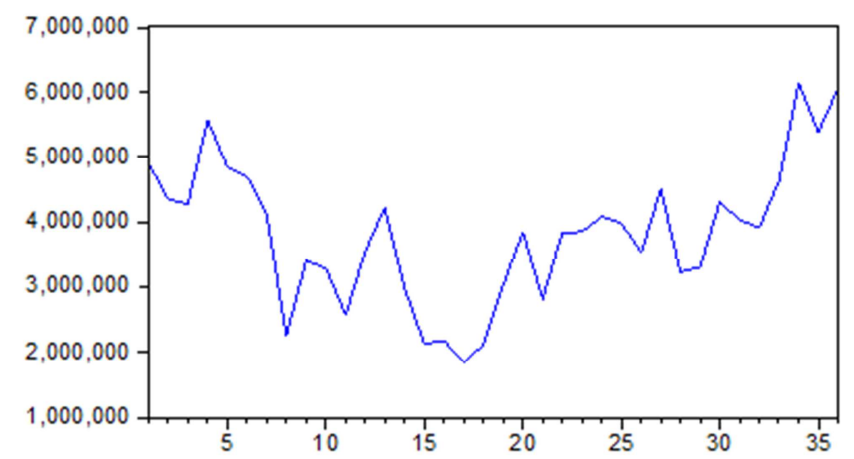

\subsection{Pre-estimation Analysis: Descriptive Statistics and Graphical Presentation}

Table 2 below, reported the descriptive statistics for variables employed in the analysis, it is found that variability is highest for Web Based Transaction (WBT), Point of Sales (POS), Interbank Transfer (INTERBANK), but lower for Mobile Payment (MOP). The table further reported the standard deviation, skewness and kurtosis coefficients and the Jarque-Bera statistics to test the null hypothesis that all our variables are normally distributed among others.
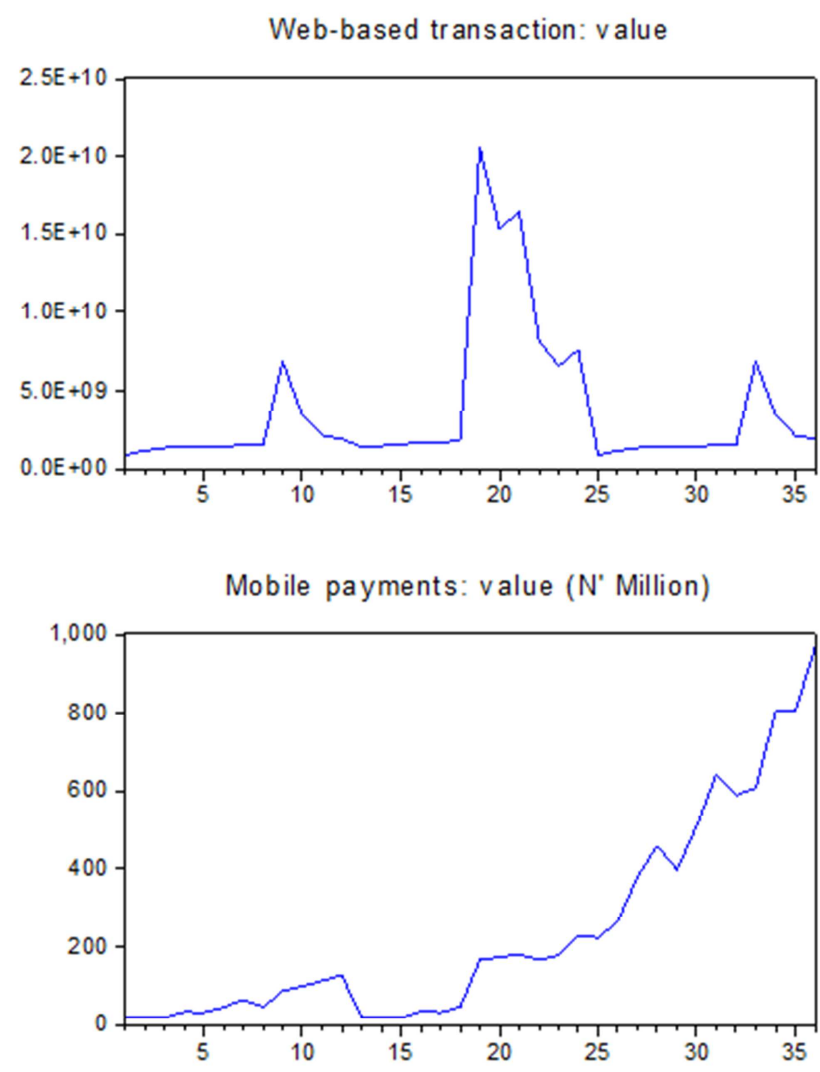

ATM trans action: Value ( $N^{\prime}$ Million)

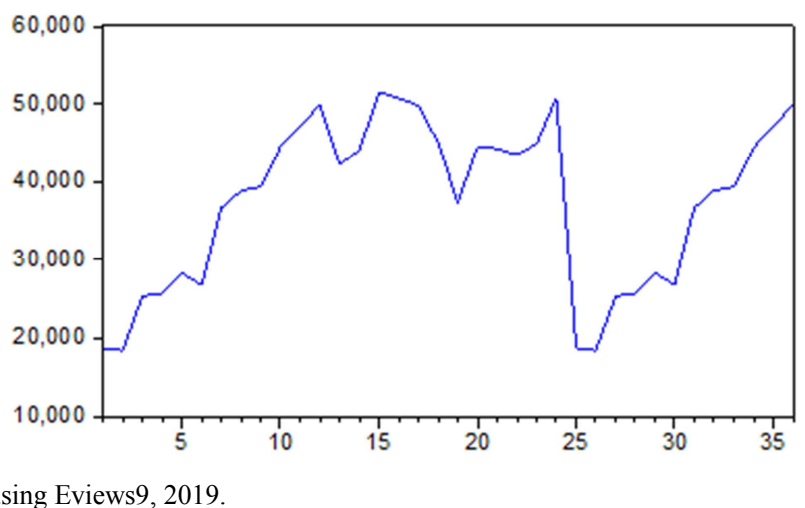

Figure 2. Time Plots of Real GDP, Web-based transaction, POS transactions, Mobile payments transactions, interbank funds transfer transaction and ATM transactions.

Based on figure two above, figure 1 within the chart illustrates the trend of Real GDP in Nigeria, it clearly shows that RGDP experience a steady growth rate between 2008 and 2009, however there was remarkably a upward surge 
second quarter 2009 to 2010. Figure no. 2 showed Web Based Transaction (WBT) witnessed a fairly stable state which was at its highest peak in the third quarter 2009 and an all-time low in first quarter 2010. Also, point of Sale (POS) transactions observed a sharp rise in fourth quarter 2008, while since the sharp rise, POS transactions have experienced decline in the third quarter of 2010, on the contrary, Mobile payment (MOP) has experienced a fairly stable rise as presented above. Indications shows Interbank Funds Transfer (INTERBANK) was on a decline between second quarter 2008 to fourth quarter 2008, and rose sluggishly from third quarter 2009 through the observed period. Automated Teller Machine (ATM) transaction started with a steady increase in first quarter 2008 till fourth quarter 2009 when it falls sharply before witnessing a fairly stable rise in first quarter 2010 throughout the observation periods.

Table 2. Descriptive Statistics for variables in the model.

\begin{tabular}{|c|c|c|c|c|c|c|}
\hline & LOGRGDP & LOGPOS & LOGWBT & LOGMOP & LOGINTERBANK & LOGATM \\
\hline Mean & 10.25207 & 20.77715 & 21.58767 & 4.707052 & 15.10010 & 10.47374 \\
\hline Median & 10.01381 & 20.73949 & 21.17442 & 4.844345 & 15.16201 & 10.58052 \\
\hline Maximum & 11.14221 & 21.43232 & 23.74701 & 6.690619 & 15.62999 & 10.84881 \\
\hline Minimum & 9.530920 & 20.35962 & 20.59181 & 2.871302 & 14.42937 & 9.824653 \\
\hline Std. Dev. & 0.555956 & 0.249849 & 0.864627 & 1.270379 & 0.294299 & 0.326337 \\
\hline Skewness & 0.308409 & 0.673867 & 1.202388 & -0.014241 & -0.574170 & -0.756623 \\
\hline Kurtosis & 1.574640 & 2.790662 & 3.198532 & 1.681427 & 2.693350 & 2.288877 \\
\hline Probability & 0.172246 & 0.257586 & 0.014329 & 0.281296 & 0.356969 & 0.130228 \\
\hline Sum & 358.8224 & 727.2003 & 755.5685 & 164.7468 & 528.5036 & 366.5807 \\
\hline Sum Sq. Dev. & 10.50897 & 2.122431 & 25.41773 & 54.87134 & 2.944801 & 3.620865 \\
\hline Observations & 35 & 35 & 35 & 35 & 35 & 35 \\
\hline
\end{tabular}

Source: Author's Computation from the Regression Results, 2019.

The series, LOGMOP, LOGINTERBANK, and LOGATM are negatively skewed and leptokurtic, while LOGRGDP, LOGPOS, AND LOGWBT were positively skewed and the Jarque-Bera statistics reject the null hypothesis of normality very strongly for all the series used in our model since all our series are having positive Jarque-Bera statistics.

Table 3. Correlation Analysis of the Variables used in the Regression Analysis.

\begin{tabular}{llllll}
\hline & LOGRGDP & LOGPOS & LOGWBT & LOGMOP & LOGINTER BANK \\
\hline LOGRGDP & 1.000000 & -0.408060 & 0.145698 & 0.913169 & 0.235540 \\
LOGPOS & -0.408060 & 1.000000 & -0.198386 & -0.235323 & 0.143476 \\
LOGWBT & 0.145698 & -0.198386 & 1.000000 & 0.290810 & -0.056058 \\
LOGMOP & 0.913169 & -0.235323 & 0.290810 & 1.000000 & 0.302173 \\
LOGINTERBANK & 0.235540 & 0.143476 & -0.056058 & 0.302173 & 1.000000 \\
LOGATM & 0.029262 & 0.104465 & 0.499708 & 0.055661 & -0.426061 \\
\hline
\end{tabular}

Source: Author's Computation from the Regression Results, 2019.

\subsection{Correlation Analysis}

In order to corroborate the descriptive statistic, Table 3 above also showed the pairwise correlation analysis of the variables used in the estimation. The results of the correlation analyses showed different signs, association and strength among variables. For instance, Web Based Transaction (WBT), Mobile payment (MOP), InterBank Transfer (INTERBANK), and Automated Teller Machine (ATM) exerts Net foreign assets positive association with Real Gross Domestic Product (RGDP), while, Point of Sale (POS) negative correlation was found with RGDP. Also, WBT and MOP has a negative correlation relationship with POS as shown in the Table 3, while INTERBANK exact negative correlation coefficient with WBT and ATM over the observation periods.

\subsection{Unit Root Test}

The unit root test is conducted using both Augmented Dickey-Fuller (ADF) test and Phillips-Perron standard unit root test in time series analysis. The results of both tests are presented in Table 4 below. The results show that none of the series is integrated of I (2) or higher. Test for stationarity shows that all variables are integrated of order I (1) and thus, stationary in at first difference.

Table 4. Unit Root Tests Results.

\begin{tabular}{lllll}
\hline \multirow{2}{*}{ Variable } & & Unit Root Tests & Order of Co-integration \\
\cline { 2 - 5 } & & ADF & -0.4777 & \multirow{2}{*}{ I (1) } \\
\multirow{2}{*}{ LOGRGDP } & Level & -0.0483 & $-3.3645^{*}$ & \\
\multirow{2}{*}{ LOGATM } & $1^{\text {st }}$ Difference & $-3.3645^{*}$ & -0.2799 & \\
& Level & -0.4627 & $-6.1677^{*}$ & (I) \\
\hline
\end{tabular}




\begin{tabular}{|c|c|c|c|c|}
\hline \multirow{2}{*}{ Variable } & & \multicolumn{2}{|c|}{ Unit Root Tests } & \multirow{2}{*}{ Order of Co-integration } \\
\hline & & ADF & PP & \\
\hline \multirow{2}{*}{ LOGINTERBANK } & Level & 0.3491 & 0.5211 & \multirow{2}{*}{$\mathrm{I}(1)$} \\
\hline & $1^{\text {st }}$ Difference & $-6.9338^{*}$ & $-6.9338 *$ & \\
\hline LOGMOP & $\begin{array}{l}\text { Level } \\
1^{\text {st }} \text { Difference }\end{array}$ & $\begin{array}{l}-1.4823 \\
-6.0898^{*}\end{array}$ & $\begin{array}{l}-1.5516 \\
-6.0898 *\end{array}$ & I (1) \\
\hline LOGPOS & $\begin{array}{l}\text { Level } \\
1^{\text {st }} \text { Difference }\end{array}$ & $\begin{array}{l}-2.008 \\
-5.3617^{*}\end{array}$ & $\begin{array}{l}-2.0245 \\
-5.6539^{*}\end{array}$ & I (1) \\
\hline LOGWBT & $\begin{array}{l}\text { Level } \\
1^{\text {st }} \text { Difference }\end{array}$ & $\begin{array}{l}-1.2378 \\
-6.6028 * *\end{array}$ & $\begin{array}{l}-1.1877 \\
-6.6884 *\end{array}$ & $\mathrm{I}(1)$ \\
\hline
\end{tabular}

Note: $* * *$ denote $1 \%$ and $5 \%$ level of significance, the optimal lag structure is determined by Schwarz Info Criterion. Source: Author's Estimation from Eview 9, 2019.

\subsection{Empirical Results of the Estimated Model}

Table 5 showed the Autoregressive Distributed Lag (ADRL) results obtained from the empirical analysis of the relationship between energy consumption and economic growth in Nigeria. The dependent variable used is Real Gross Domestic Product (RGDP), while the independent variables are automated teller machine (ATM), Interbank Transfer (INTERBANK), Mobile Payment (MOP), Point of Sale (POS), and Web Based Transaction (WBT). All variables were estimated using their raw state as the use of natural logarithm, run into loss of data for some variable and estimation problem.

Table 5. The ARDL Regression Results.

\begin{tabular}{|c|c|c|c|c|}
\hline \multicolumn{5}{|c|}{ Dependent Variable: LOGRGDP } \\
\hline \multicolumn{5}{|l|}{ Method: ARDL } \\
\hline \multicolumn{5}{|c|}{ Selected Model: ARDL $(3,3,3,3,3,3)$} \\
\hline Variable & Coefficient & Std. Error & T-Statistic & Prob.* \\
\hline LOGRGDP (-1) & 1.590231 & 0.231408 & 6.871993 & 0.0001 \\
\hline LOGRGDP (-2) & -0.862433 & 0.292213 & -2.951379 & 0.0184 \\
\hline LOGRGDP (-3) & 0.295707 & 0.192017 & 1.540005 & 0.1621 \\
\hline LOGPOS & 0.088233 & 0.064176 & 1.374844 & 0.2065 \\
\hline LOGPOS $(-1)$ & 0.061706 & 0.062145 & 0.992924 & 0.3498 \\
\hline LOGPOS (-2) & -0.245752 & 0.073220 & -3.356376 & 0.0100 \\
\hline LOGPOS (-3) & 0.177249 & 0.060627 & 2.923586 & 0.0192 \\
\hline LOGWBT & 0.023611 & 0.010271 & 2.298698 & 0.0506 \\
\hline LOGWBT (-1) & 0.014876 & 0.009600 & 1.549518 & 0.1599 \\
\hline LOGWBT (-2) & -0.010845 & 0.010066 & -1.077433 & 0.3127 \\
\hline LOGWBT (-3) & 0.024326 & 0.013535 & 1.797310 & 0.1100 \\
\hline LOGMOP & 0.014622 & 0.014200 & 1.029722 & 0.3333 \\
\hline LOGMOP (-1) & -0.010288 & 0.013626 & -0.755065 & 0.4719 \\
\hline LOGMOP (-2) & -0.028328 & 0.014699 & -1.927170 & 0.0901 \\
\hline LOGMOP (-3) & 0.020275 & 0.016585 & 1.222483 & 0.2563 \\
\hline LOGINTERBANK & -0.075218 & 0.032617 & -2.306090 & 0.0500 \\
\hline LOGINTERBANK (-1) & 0.027307 & 0.043134 & 0.633061 & 0.5444 \\
\hline LOGINTERBANK (-2) & -0.012740 & 0.030683 & -0.415231 & 0.6889 \\
\hline LOGINTERBANK (-3) & -0.061202 & 0.031558 & -1.939333 & 0.0884 \\
\hline LOGATM & -0.054233 & 0.026632 & -2.036345 & 0.0761 \\
\hline LOGATM (-1) & -0.056730 & 0.026291 & -2.157787 & 0.0630 \\
\hline LOGATM (-2) & 0.020180 & 0.023372 & 0.863420 & 0.4130 \\
\hline LOGATM (-3) & -0.055287 & 0.026835 & -2.060263 & 0.0733 \\
\hline $\mathrm{C}$ & 0.365958 & 2.189942 & 0.167109 & 0.8714 \\
\hline R-squared & 0.999736 & Mean deper & & 10.31371 \\
\hline Adjusted R-squared & 0.998976 & S. D. depen & & 0.541359 \\
\hline S. E. of regression & 0.017326 & Akaike info & & -5.159474 \\
\hline Sum squared resid & 0.002402 & Schwarz cri & & -4.060172 \\
\hline Log likelihood & 106.5516 & Hannan-Qu & & -4.795086 \\
\hline F-statistic & 1315.455 & Durbin-Wat & & 2.072033 \\
\hline Prob (F-statistic) & 0.000000 & & & \\
\hline
\end{tabular}

*Note: p-values and any subsequent tests do not account for model selection.

Source: Author's computations from Eviews 9.

\subsection{Explanation of Results}

The results of the ARDL regression show that at all levels of significance, the coefficients of the first and third years real GDP (lagged), POS (lagged first and third years), WBT (first and third lagged years), INTERBANK first year lagged, mobile banking payment (MOP) current and third year, and ATM lagged second period shows that they are 
statistically significant. This implies that point of sales transaction (POS), web based transactions (WBT), inter bank transfers (INTERBANK), mobile banking payment system (MOP), and automated teller machine (ATM) transactions are part of the major determinant factor influencing real GDP growth output in Nigeria, while other lagged years especially the second period are not statistically significant and are less important in driving real GDP output, as reflected in our results. The result revealed a negative elasticity coefficient of -0.075 for INTERBANK on real GDP output growth in Nigeria, though significant at 95 percent confidence interval (probability of 0.05 ). This means that a $1.0 \%$ rise in INTERBANK transfer transactions would dampen growth in GDP per capita by $7.5 \%$, while a similar rise in WBT would raise it by a coefficient of 0.023 (2.3 percent) with a significant value of 0.05. Mobile banking payment (MOP) although with a coefficient of 0.028 ( -2.8 percent) is slightly negatively statistically significant at 0.09 probability. Point of Sales (POS) is statistically significant at (0.01 probability) and contributes to the real GDP growth by an increase of 17 percent. ATM based transactions contributes significantly based on a probability of (0.06) in the first period, but its contribution to the real GDP growth is negative (-5.0 percent), the reason is that ATM transaction encourages more cash possessions and may not yield the required goal of low cash based transactions within Nigeria's banking populace. In general, the fit of the regression equations in Table 5 is very good (coefficient of determination $\mathrm{R}=0.99$ and adjusted $\mathrm{R}^{2}=0.99$ ). The $\mathrm{R}$-squared shows that all the independent variables in our model explain approximately $99 \%$ of the variations in output growth per capita (dependent variable) in the period under consideration. Also, the joint F-test statistic value of 1315.455 was found significant $(0.0000)$ at all levels, showing the joint test results by the inclusion of all the variables in the model. Pertinent to the above, the Durbin-Watson (DW) statistic (measures for the presence of autocorrelation in the model) is 2.07 , it is noticed therefore, that our model is free from autocorrelation as the value is $\leq 2$, as expected by the rule of thumb. This means that the model is reliable in explaining the relationship between electronic banking and economic growth in Nigeria.

\section{Conclusion}

Technology (especially electronic banking) has unarguably made lives easier. It has cut across distance, space and even time. One of the technological innovations in banking, finance and commerce is the electronic payments. The electronic payment system provides greater freedom to individual in paying their taxes, licences, fees, bills, fines and purchase at unconventional locations and at whichever time of the day. The success of e-electronic payment systems largely depend on consumer preferences, ease of use, cost, industry, agreement, authorization, security, non-reputability and acceptability. From the literature reviewed, electronic payment system was introduced in Nigeria in the year 2012. However, the electronic payment economic system has not been fully actualized. This means that the assertion of the technology acceptance model which connotes that's end users tends to take up new technological innovations has not been fully actualized in Nigeria. Prior to the implementation of the electronic payment system, Nigeria was a huge cash-based economy.

\subsection{Empirical Findings}

The results obtained from the tests reveal that the independent variables employed in the model ((Values of automated teller machine transactions (ATM), interbank money transfers (INTERBANK), point of sale (POS) transactions, web based banking (WBT) and mobile banking payments (MOP)) explains about $99 \%$ of the systematic variation in the dependent variables. Automated teller machines have a positive significant impact on economic growth, based on a probability of (0.06), but its contribution to the real GDP growth is negative (-5.0 percent). This means the ATM based transaction encourages more cash, possessions and may not yield the required goal of low cash based transactions within Nigeria's banking populace. POS contributes 17 percent growth to the real GDP growth in Nigeria, web based transactions (WBT), contributes 2.3 percent to the real GDP growth, but INTERBANK transactions, has an insignificant impact on GDP growth while MOP has a negative contribution to the impact on real GDP growth. Point of Sales (POS) transactions is also the most patronized electronic banking tool and this is seen from the descriptive analysis, followed by web base transactions (WBT). POS and WBT have the highest average amongst all other variables. The electronic banking tools overall, have a significant impact on real economic growth.

\subsection{Recommendations}

From the analysis conducted in this study, it is important that the following recommendations be made to improve the output performance of the economic and banking sectors in Nigeria. The banks and electronic payment service providers should ensure that personal data collected, and other sensitive materials should not tamper with and efforts should be made to design or improve on the internet security framework to check online fraud and fraudulent activities. There should be adequate legislation on all aspects of the operations of the ebanking and cashless system so that both the operators of the system and the public can be adequately protected. Financial Technology (Fintech) companies should be encouraged and more companies registered to facilitate ease of electronic banking. Public enlightenment programs and awareness programs on the electronic payment system should be put in place by the Central Bank of Nigeria ( $\mathrm{CBN}$ ) especially education on how to transact on the web to foster better understanding by the banking public with the system. This will create awareness and entice the unbanked people in the banking system and thereby more than double the real GDP 
growth.

Although on the average, point of sales transactions (POS) and web based transfer (WBT) are the most patronized during the period of study, more awareness should be embarked upon and transaction charges reviewed downwards to encourage more patronage, and this will enhance epayments and has the potential to grow the economy. The central bank of Nigeria should adopt new policies that will encourage business owners and companies to settle transactions electronically. This will help create a vehicle of change needed to drive the electronic economic system. EBanking products must also be re-engineered to make electronic payment effortless, which will steer the country toward a more robust electronic payments economy. Some of the product is ATM machines and INTERBANK transfers should have added features which will make them more attractive for use by Nigerians and hence, promote the ebanking and payment system. This is because they have an insignificant impact on electronic banking.

\section{References}

[1] Acha I. A, Kanu. C \& Agu. G. A (2017). Cashless Policy in Nigeria: The Mechanics, Benefits and Problems, Innovative Journal of Economics and Financial Studies Vol. 1, No. 1, pp: 28-38, 2017.

[2] Apergis, N., \& Payne, J. E. (2010). Renewable energy consumption and economic growth: evidence from a panel of OECD countries. Energy policy, 38 (1), 656-660.

[3] Acha, I. A. (2008a). Electronic banking in Nigeria: Concepts, challenges and prospects. International Journal of Development and Management Review, 3 (1): 88-97.

[4] Akhalumeh, P. B., \& Ohiokha, F. (2012). Nigeria's cashless economy: the imperatives. International Journal of Management and Business Studies, 2 (2), 31-36.

[5] Ajzen, I. (1985). From intentions to actions: A theory of planned behavior. In Action control (pp. 11-39). Springer Berlin Heidelberg.

[6] Biagio, B. \& Massimo, C. (2001), "The Oversight of the Payments Systems: A Framework for the Development and Governance of Payment Systems in Emerging Economies", World Bank Report, July 2001.

[7] Central Bank of Nigeria (2015). Payments system transformation: Cash -less Nigeria implementation: 2013.

[8] Claudia, C., \& Grauwe, P. (2001). Monetary policy in a cashless society. Brussel CEPR Discussion Study.

[9] Central Bank of Nigeria (2011). Towards a cashless Nigeria: Tools \& strategies. Nigerian Journal of Economy, 3 (2): 344 50.

[10] Daily Sun (2017). Daily Sun Newspaper: Nigeria's Internet Users Rise To 91.6m. Daily Sun Pg 2 (Thursday, July 27, 2017).
[11] Davis, F. D., Bagozzi, R. P., \& Warshaw, P. R. (1989). User acceptance of computer technology: a comparison of two theoretical models. Management Science, 35 (8), 982-1003.

[12] Ezeokoli, F. O., Ugochukwu, S. C., Agu, N. N., \& Akabogu, S. C. (2016). An assessment of the use, benefits and challenges of the 'cash-lite' policy, for construction projects In Anambra State, Nigeria. European Scientific Journal, 12 (16).

[13] Ejiro, O. (2012). What Nigerians think of the cashless economy policy. Nigerian Journal of Economy, 4 (6): 97-102.

[14] Fishbein, M., \& Ajzen, I. (1975). A Bayesian analysis of attribution processes. Psychological bulletin, 82 (2), 261.

[15] Ikpefan, Ochei Ailemen and Enobong, Akpan and Osuma, Godswill and Evbuomwan, Grace O. and Ndigwe, Chisom (2018) Electronic Banking And Cashless Policy In Nigeria. International Journal of Civil Engineering and Technology (IJCIET), 9 (10). pp. 718-731. ISSN 0976-6316.

[16] Muhibudeen, L., \& Haladu, A. (2015). The impact of cash less policy tools on money circulating outside Nigerian banks. International Journal of Business, Economics and Law, 8 (3), 47-52.

[17] Obi, V. (2011). Imperatives of advancing cashless Nigeria. Posted online on june 13, 2011 accessed October, 2019.

[18] Omojolaibi, J. A., Mesagan, E. P., \& Oladipupo, T. D. (2016). The dynamics of electricity consumption and private investment in Nigeria. Economic Issues Journal Articles, 21 (2), 33-51.

[19] Punch (2012). Cash-less: Banks begin roadshow in Lagos $\mathrm{http}: / /$ www.punchng.com/.../cash-less-banks-begin-roadshowin....

[20] Paschal Okafo (2019). InterSwitch Verve PIN Chip Card ATM Secure e-payment. https://www.naijatechguide.com/2009/04/interswitch-vervepin-chip-card-atm.html.

[21] Rogers, E. M. (1976). New product adoption and diffusion. Journal of consumer Research, 2 (4), 290-301.

[22] Rogers, E. M. (1995). Diffusion of Innovations: modifications of a model for telecommunications. In Die Diffusion von Innovationen in der Telekommunikation (pp. 25-38). Springer Berlin Heidelberg.

[23] Summers, B. J. (2012). "Payment Systems-Design, Governance and Oversight," London: Central Banking Publications.

[24] Shih, Y. Y., \& Fang, K. (2004). The use of a decomposed theory of planned behavior to study Internet banking in Taiwan. Internet Research, 14 (3), 213-223.

[25] Tee, H. H., \& Ong, H. B. (2016). Cashless payment and economic growth. Financial Innovation, 2 (1), 4.

[26] Woodford, M. (2003). Interest \& price: Foundation of a theory of monetary policy. Princeton University Press: Yaqub, J. O., Bello, H. T., Adenuga, I. A. and Ogundeji, M. O. (2013). The cashless policy in Nigeria: Prospects and challenges. International Journal of Humanities and Social Science, 3 (3): 200-212. 